\title{
KOMUNIKASI NON VERBAL KANURI BLANG PADA MASYARAKAT TANI UNTUK MENCIPTAKAN TANAM SERENTAK DI DESA KREUNG TINGGAI KECAMATAN SAMATIGA KABUPATEN ACEH BARAT
}

\author{
Khori Suci Maifianti \\ Program Studi Sosial Ekonomi Pertanian, Universitas Teuku Umar \\ Email: khorism@utu.ac.id
}

\begin{abstract}
Communication is done not only by words but also by non verbal activity that has been dealt. The farmers of Kreueng Tinggai, Samatiga, Aceh Barat have been done non verbal communication after ritual "kanuri blang". This study used qualitative method, where the source of data were taken from observation, deep interview, and focus group dissussion (FGD). Non verbal communication used is flag. When the white flag waves is means that it is sowing time, and when the green flag waves, it is planting time. The colour of flag is used to acuelerate the information so the people are able to plant together.
\end{abstract}

Keywords : Communication Non Verbal, Kanuri Blang, Community Farmers

\section{PENDAHULUAN}

Menteri pertanian mencanangkan gerakan tanam serentak mendukung program peningkatan produksi beras nasional (P2BN) tahun 2015. Hal ini dirasakan oleh seluruh masyarakat tani di Indonesia, khususnya di Aceh. Pertanian merupakan usaha yang paling utama bagi sebagian masyarakat Aceh. Ini tergambar pada semboyan nenek moyang masyarakat Aceh "Pangulèe hareukat meugoe" yang artinya usaha yang paling utama adalah pertanian. Masyarakat Aceh juga memiliki pandangan bahwa menanam padi merupakan "berkah", sehingga makanan pokoknya yaitu beras. Selain itu, dukungan Qanun Nomor 10 Tahun 2008 tentang lembaga adat juga menjadi pendukung peningkatan hasil produktivitas padi.

P2BN tidak akan berhasil tanpa dukungan dari lembaga adat yang ada di Aceh. Sebagaimana Uphoff (1985) peringatkan pemerintah haruslah memiliki komitmen terhadap pembangunan pedesaan yang seimbang melalui organisasi-organisasi lokal yang akan mampu menjembatani transfer sumber daya dari pusat ke daerah secara signifikan. Lembaga adat juga merupakan suatu komponen dari struktur sosial yang berorientasi pada nilai-nilai kebudayaan yang diperankan, berkenaan dengan mempertahankan sumber daya alam dan kelestarian lingkungannya dalam peningkatan kesejahteraan dan kelangsungan hidupnya sesuai dengan bidangnya masing-masing demi tercapainya tujuan pembangunan (Yusoef et.al, 2011). Peran-peran tersebut telah terinternalisasi dalam kelompok masyarakat didasari pada pengetahuan, nilai, dan norma terhadap kehidupan. Lembaga adat yang berperan dalam pertanian adalah keujreun blang, dan memiliki ritual di bidang pertanian yang disebut kanuri blang.

Keujreun blang merupakan lembaga adat tingkat gampong (desa) yang tugasnya membantu geuchik (kepala desa) di bidang persawahan. Yulia et al. (2012) mengatakan keujreun blang adalah lembaga adat yang merupakan salah satu faktor pendukung dalam roda perekonomian di bidang pertanian, sehingga menjadi salah satu unsur dalam 
meningkatkan produksi padi sawah. Kanuri blang dilakukan setelah adanya koordinasi dengan semua unsur terkait. Setelah melakukan rapat dan penentuan turun ke sawah ditetapkan, maka keujreun blang desa mengajak petani mengadakan Kanuri blang di gampong masing-masing sesuai dengan yang ditetapkan. Semua petani yang akan turun sawah diwajibkan untuk menghadiri pelaksanaan kanuri blang. Kanuri blang salah satu contoh kegiatan komunikasi.

Kegiatan komunikasi memang merupakan kegiatan mengirim atau menerima pesan, namun pada dasarnya pesan sama sekali tidak berpindah, yang berpindah adalah makna pesan tersebut. para ahli komunikasi mengatakan bahwa komunikasi adalah kegiatan "pertukaran makna", makna itu ada di dalam setiap orang yang mengirim pesan. Jadi, makna bukan sekedar kata-kata verbal atau perilaku non verbal, tetapi makna adalah pesan yang dimaksudkan oleh pengirim dan diharapkan akan dimengerti pula oleh penerima (Liliweri 2007). Aktivitas komunikasi yang terjadi dalam ritual kanuri blang merupakan wujud kegiatan komunikasi.

Ritual kanuri blang merupakan sebuah tempat interaksi sosial masyarakat tani. Hubungan yang terjadi dalam ritual ini berlangsung antara individu dengan individu, antara masyarakat dengan masyarakat, antara individu dengan masyarakat dan antara masyarakat dengan Allah SWT. Hubungan timbal balik tersebut dinamakan interaksi sosial. Proses interaksi sosial tersebut berlangsung menurut suatu pola, yang sebenarnya berisikan harapan-harapan masyarakat tentangapa yang sepantasnya dilakukan dalam hubunganhubungan sosial.

Pada umumnya orang tergerak untuk bertindak berdasarkan makna yang diberikan pada orang, benda, dan peristiwa. Makna-makna ini diciptakan dalam bahasa dan tindakan yang digunakan orang baik untuk berkomunikasi dengan orang lain maupun dengan dirinya sendiri, atau pikiran pribadinya. Bahasa memungkinkan orang untuk mengembangkan perasaan mengenai diri dan untuk berinteraksi dengan orang lainnya di dalam sebuah komunikasi maupun cakupan yang lebih luas. Berdasarkan adanya komunikasi verbal dan komunikasi non verbal yang ada dalam ritual kanuri blang maka penulis mencoba untuk mengkaji makna sebuah lambang atau bendera yang mulai dikibar setelah usai ritual kanuri blang yang merupakan kebiasaan masyarakat tani di Desa Kreung Tinggai Kecamatan Samatiga Aceh Barat.

\section{Tujuan dan Manfaat}

Tujuan dari kajian ini adalah untuk mengkaji makna bendera kanuri blang pada masyarakat tani untuk menciptakan tanam serentak di Desa Kreung Tinggai Kecamatan Samatiga Kabupaten Aceh Barat.

\section{METODE PENELITIAN}

Penelitian ini dilakukan dengan menggunakan pendekatan kualitatif, yakni metode etnografi komunikasi. Pengumpulan data dilakukan melalui pengamatan pada saat proses kanuri blang berlangusng, wawancara mendalam dan focus group discussion (FGD). Informan dalam penelitian ini terdiri dari geuchik, keujreun blang, teungku imum, ketua kelompok tani, petani, pemuda, dan penyuluh. Analisis data digunakan cara Miles dan Huberman (2007) yaitu reduksi data, penyajian data dan penarikan kesimpulan/verifikasi. 


\section{PEMBAHASAN}

\section{Masyarakat Tani}

Petani, aparat desa, pemuda, keujreun blang, pemuka adat, ketua kelompok tani dan penyuluh pertanian, mereka merupakan masyarakat tani. Ini dikarenakan saat kanuri blang mereka sekumpulan yang memiliki peran masing-masing yang saling berinteraksi satu dengan yang lain yang akan membentuk suatu perilaku sosial. Ritual kanuri blang merupakan wujud dari kebudayaan yang berpola dalam masyarakat tani.

Masyarakat tani memegang teguh peribahasa Aceh "Pangulee hareuket meugoe" (usaha yang paling utama ialah pertanian) dan untuk yang kedua "kaya meuih han meusampé, kaya padé meusamporeuna" (kaya emas tidak cukup, kaya padi adalah hal yang amat sempurna). Masyarakat tani di Kecamatan Samatiga menggunakan kalender bulan Islam dan juga menggunakan kalender musim yang berhubungan dengan matahari dan menghitung tahun menurut keadaan bulan terhadap kelompok bintang kala (keuneunong). Hal ini tergambar dari hasil wawancara dengan keujruen blang mukim.

Jadwal pula pas geutanyoe memang ta pakèk kalender tandon nyang geujôk le BP3K, tapi kalender nyan nakeuh dari has musyawarah keujruen blang, imuem mukim, dan ketua kelompok tani. Has musyawarah nyoe nakeuh jadwal pula pas nyang jikalon dari buleuen Islam ngon keuneunong. (Wawancara Bapak J.P, 02/12/2013).

Diterjemahkan menjadi:

Musim tanam kita memang menggunakan kalender musim tanam yang diberikan oleh BP3K tetapi kalender yang dikeluarkan oleh BP3K itu hasil dari musyawarah keujruen blang, imuem mukim, dan ketua kelompok tani. Hasil musyawarah ini membahas musim tanam yang dilihat dari bulan Islam dan keuneunong. (Wawancara Bapak J.P, 02/12/2013).

Adanya pandangan masyarakat bahwa menanam padi itu "berkah" dan bernilai magis. Hal itu terkait dengan kedudukan padi sebagai sumber makanan pokok dan mungkin relevan dengan pandangan tradisi pra-Islam yang menempatkan tanaman padi sebagai jelmaan Dewi Sri. Masyarakat Kecamatan Samatiga menyebutnya bahwa bertani padi bukan sekedar kerja, di dalam pekerjaan itu terdapat "berkah". Hal ini terkait dengan hasil produk kerja petani yang menghasilkan kebutuhan pangan yang tidak dapat ditangguhkan ketersediaannya bagi kelangsungan kehidupan manusia. Bila dikaji dalam pemahaman Islam, tidak ada referensi yang menyebutkan pekerjaan tani lebih mulia daripada pekerjaan lainnya. Hal itu anggapan umum yang diturunkan turun-temurun, sedikitnya dipengaruhi pula oleh budaya Hindu yang menempatkan padi sebagai penjelmaan Dewi Sri. Karena itu, kebertahanan sebagian besar masyarakat pada tradisi tani sawah sedikit banyak berkaitan dengan pandangan lokal ini.

\section{Kanuri Blang}

Pertanian sawah di Aceh sejak dulu disebut dengan meugoe. Dalam meugoe, masyarakat Aceh juga membuat peraturan-peraturan yang kemudian diwariskan secara turun-temurun menjadi adat meugoe. Adat meugoe ini merupakan hasil kesepakatan bersama yang ditetapkan dalam kanuri blang yang sebagian isinya adalah warisan budaya. Contoh adat meugoe yang merupakan warisan budaya adalah pantangan memasang bubu (bube) di sawah, menjemur dan menumbuk padi selama 7 hari terhitung sejak pelaksanaan 
kanuri blang. Adat meugoe juga meliputi tentang waktu turun ke sawah, mekanisme pembagian air, dan perawatan jaringan air.

Menurut Hasballah (2007), kanuri blang, agak khusus sifatnya, dilakukan setahun sekali ketika musim bersawah akan dimulai. Beberapa ekor sapi dipotong di suatu tempat yang dianggap keramat, biasa di kuburan orang ternama (Teungku di Blang, atau tokoh pertanian yang telah lama tiada). Sering kanuri ini dilaksanakan di hulu sungai, di tengah sawah atau di tempat di mana pohon tumbuh di tepi hutan. Untuk tingkatan satu aliran sungai kecil, masyarakat biasanya memotong biri-biri. Peserta kanuri membawa bu kulah (nasi bungkus dengan daun pisang yang diasapi), bu kulah di sajikan kepada tetamu terhormat yang diundang dari kecamatan, atau mukim tetangga. Setelah upacara membaca doa-doa, maka seseorang tokoh terkemuka, seperti kepala mukim, atau kujruen blang, memberikan pengumuman tertentu. Seperti kapan harus membersihkan selokan, memperbaiki irigasi desa, awal musim membajak lahan, atau saat mulai menabur benih. Ini merupakan komando, dan koordinasi antara petani di hulu dan di hilir agar distribusi air bisa merata.

Kanuri blang dipimpin oleh Keujreun Blang. Dalam Qanun Aceh Nomor 10 Tahun 2008 tentang Lembaga Adat, Pasal 1 Ayat 22, keujreun blang sebagai orang yang memimpin dan mengatur kegiatan usaha di bidang persawahan. Keujruen blang adalah seseorang yang berpengalaman dan paham di bidang penataan pertanian yang mempunyai posisi sebagai bagian dari tim asistensi kepala gampông (geuchik) dalam memakmurkan petani. Pengangkatannya dilakukan melalui jalan musyawarah oleh masyarakat. Figur keujruen blang didasarkan pada kriteria petani yang berkepribadian tekun dan disiplin, berpengalaman dalam bidang kemasyarakatan, menguasai hukum adat pertanian (meugoe), dan memahami keadaan yang dipengaruhi oleh hidrologis wilayah (keuneunong).

\section{Komunikasi Non Verbal}

Komunikasi ritual dapat dimaknai sebagai proses pemaknaan pesan sebuah kelompok masyarakat. Mulyana (2010) mengatakan suatu komunitas sering melakukan upacara-upacara berlainan sepanjang tahun dan sepanjang hidup mulai dari kelahiran, sunatan, ulang tahun, pertunangan, siraman, pernikahan hingga upacara kematian. Dalam acara itu orang mengucapkan kata-kata atau menampilkan perilaku-perilaku simbolik. Contoh yang dapat dikemukakan adalah upacara Natoni di Nusa Tenggara Timur (Andung 2010), Kepala Menyan di Sumatera Selatan (Yenrizal 2010), Masquerades di Afrika (Ajala 2011).

Dalam komunikasi ritual adanya penggunaan simbol-simbol yang unik yang digunakan secara turun temurun, sehingga masyarakat yang melakukan ritual memiliki pemaknaan yang sama. Ini akan terciptanya komunikasi efektif. Seperti yang dikemukakan oleh Dewi (2007) bahwa komunikasi akan efektif apabila terjadi pemahaman yang sama dan pihak lain terangsang untuk berpikir atau melakukan sesuatu. Simbol-simbol merupakan salah satu komunikasi nonverbal. Menurut Samovar dan Porter dalam Mulyana (2010), komunikasi non verbal mencakup semua rangsangan (kecuali rangsangan verbal) dalam suatu setting komunikasi, yang dihasilkan oleh individu dan penggunaan lingkungan oleh individu, yang mempunyai nilai pesan potensial bagi pengirim atau penerima.

Salah satu contoh komunikasi non verbal adalah penggunaan bendera pada masyarakat tani di Desa Kreung Tinggai pada saat pelaksanaan kanuri blang sampai masuknya masa panen. Warna bendera yang dikibarkan di tengah persawahan mengandung perbedaan makna. Setiap warna memiliki perintah masing-masing. Bendera adalah contoh dari komunikasi non verbal yang menggunakan artefak. Artefak adalah benda apa saja yang dihasilkan kecerdasan manusia (Mulyana, 2010).

Masyarakat Tani di Desa Kreung Tinggai melakukan aktivitas komunikasi non 
verbal setelah usainya ritual kanuri blang. Ini mempermudah tugasnya keujreun blang untuk menyampaikan informasi tanpa harus mengumpulkan masyarakat tani. Dari hasil penelitian ada dua warna bendera yang digunakan oleh masyarakat tani yaitu warna putih dan warna hijau. Jika bendera warna putih dikibarkan dipertengahan sawah artinya waktunya untuk menabur bibit, dan jika bendera hijau artinya waktu mulainya menanam. Penggantian bendera ini dilakukan oleh keujreun blang.

Dengan adanya bendera ini, mempermudah dan mempercepat dalam penyampaian pesan sehingga diharapkan masyarakat tani patuh kepada instruksi keujreun blang yang nantinya mempengaruhi tindakan petani untuk penanaman serentak. Kanuri blang dalam pelaksanaannya bersifat santai tetapi serius. Keseriusan ini diharapkan agar petani mematuhi peraturan yang telah disampaikan dalam pidato kanuri blang. Terhadap petani yang tidak mematuhinya tidak akan diberi sanksi adat tetapi hanya akan dikucilkan oleh masyarakat setempat.

\section{PENUTUP}

Kegiatan komunikasi tidak hanya dilakukan dengan menggunakan kata-kata tetapi juga menggunakan non-verbal yang telah disepakati bersama. Masyarakat Tani Desa Kreung Tinggai Kecamatan Samatiga Kabupaten Aceh Barat juga menggunakan komunikasi non verbal setelah selesainya ritual kanuri blang. Komunikasi non verbal yang mereka gunakan yaitu bendera. Jika yang berkibar bendera putih artinya waktu untuk menabur bibit, dan jika bendera hijau yang berkibar maka sudah waktunya untuk menanam.

\section{DAFTAR PUSTAKA}

Dedy Mulyana, Ilmu Komunikasi, Suatu Pengantar, Remaja Rosda Karya, Bandung, 2010.

Dewi K, Marcel P R, Ambarwati D R, Christanto H, Uran G, Emi, Christoporus. 2008. Relasi Gender dalam Budaya Manggarai. Denpasar(ID): Veco Indonesia.

Geertz. C. 1973. The Interpretation of Cultures. New York (USA): Free Press.

Hikmat R H. 2001. Strategi Pemberdayaan Masyarakat. Bandung(ID): Humaniora Utama Press.

Martiningsih N Gst.Ag.Gde Eka. 2012. Pelestarian Subak Dalam Upaya Pemberdayaan KearifanLokal Menuju Ketehanan Pangan dan Hayati. Jurnal Bumi Lestari. Diunduh 2013 Oktober 9; 12(2):303-312: ojs,unud.ac.id.

Nusir, Syahrowi R, Latif B, Apendi A, Drajat S, Theresia S A. 2010. Eksistensi Kearifan Lokal dalam Pengelolaan Sumber daya Kelautan dan Perikanan. Hidayati K, Baekhaki K, editor. Jakarta(ID): Direktorat Pemberdayaan Masyarakat Pesisir.

Syarif, M. 2010. Memudarnya Bari dan Kelembagaan Mabari (Studi pada komunitas petani kelapa di dua desa di Kabupaten Halmahera Barat [thesis]. Bogor : Institut Pertanian Bogor.

Syarif, S. 2005. Gampong dan Mukim di Aceh 
Miles, Matthew B, Huberman A. Michael. Analisis Data Kualitatif. Tjetjep Rohendi Rohidi, penerjemah. Jakarta (ID): Universitas Indonesia. Terjemahan dari Qualitative Data Analysis.

Rustinsyah. 2012. Local Culture Revitalization as A Strategy for Rural Community Empowerment (A Case Study in Village Purification Ritual in Agricultural Community at Kebonrejo Village, Subdistrict Kepung, Distric Kediri, East Java, Indonesia. Jurnal research on Humanities and Social Sciences. Diunduh 2013 Oktober 9; 2(8):60- 64.ISSN 2222-2863. www.iiste.org.

Suradisastra K. . 2011. Revitalisasi Kelembagaan untuk Mempercepat Pembangunan Sektor Pertanian dalam Era Otonomi Daerah. Jurnal Pengembangan Inovasi Pertanian. 4(2):118-136.

Uphoff, Norman. 1986. Local Institutional Development. Cornell(USA): Kumarian Press.

Yulia, Sulaiman, dan Herinawati. 2012. Pemberdayaan Fungsi Dan Wewenang Keujreun Blang Di Kecamatan Swang Aceh Utara (dalam pelaksanaan Qanun Nomor 10 Tahun 2008 tentang lembaga adat). Jurnal Dinamika Hukum. Diunduh 2013 Mei 19; 12(2)368-378. fh.unsoed.ac.id.

Yenrizal. 2010. Komunikasi ritual Dalam Tradisi Kepala Menyan. Annual Conference on Islamic Studies (ACIS) ke 10.

Marana M. 2010. Culture and Development; Evolution and Propects. Spain(ESP): Unesco Etxea. 